\title{
Dipyridamole infusion protocols for absolute myocardial blood flow quantitation by PET
}

\author{
René R. Sevag Packard, MD, PhD \\ a Division of Cardiology, Department of Medicine, David Geffen School of Medicine, University \\ of California, Los Angeles, CA \\ b Ronald Reagan UCLA Medical Center, Los Angeles, CA \\ c Veterans Affairs West Los Angeles Medical Center, Los Angeles, CA
}

Received Nov 27, 2018; accepted Nov 28, 2018

doi: $10.1007 / \mathrm{s} 12350-018-01554-2$

\section{See related article, pp. 1820-1828}

In this issue of the Journal of Nuclear Cardiology, F. Harel et al compare the effect of two dipyridamole dosing protocols on absolute myocardial blood flow (MBF). ${ }^{1}$ Patients were retrospectively identified over a 12-month period in a single center, and only those patients who had a coronary artery calcium (CAC) score available and whose $\mathrm{CAC}$ score was 0 were retained for analyses. Additional exclusion criteria including myocardial perfusion imaging (MPI) scans with a sum stress score $>3$, and body mass index (BMI) $>45$, were applied. In the first half of the study period, patients underwent a 4-minute dipyridamole infusion protocol $(n$ $=65$, standard dipyridamole dose of $0.56 \mathrm{mg} / \mathrm{kg}$ over 4 minutes), and during the second half, patients underwent a 5-minute protocol $(n=82$, higher dipyridamole dose of $0.70 \mathrm{mg} / \mathrm{kg}$ over 5 minutes). ${ }^{82} \mathrm{Rb}$-chloride was used as the positron emission tomography (PET) radiopharmaceutical in all patients.

Societal guidelines for the diagnosis of patients with stable coronary artery disease (CAD) vary across countries, ${ }^{2}$ and the growing use of pharmacological stress testing for MPI-sometimes inappropriately in

\footnotetext{
Funding Dr. Packard is supported by AHA Grant 16SDG30910007 and the Cardiovascular Research Foundation of Southern California. Reprint requests: René R. Sevag Packard, MD, PhD, Division of Cardiology, Department of Medicine, David Geffen School of Medicine, University of California, 10833 Le Conte Ave., CHS Building Room 17-054A, Los Angeles, CA; rpackard@mednet.ucla.edu

J Nucl Cardiol 2020;27:1829-31.

$1071-3581 / \$ 34.00$

Copyright (C) 2018 American Society of Nuclear Cardiology.
}

eligible patients with exercise capacity who may achieve adequate cardiac workload-has led to changes in guideline recommendations in the United States. ${ }^{3}$ Stress agents used for MPI are predominantly vasodilator drugs, either the nonselective adenosine receptor agonists adenosine or dipyridamole, or the (relatively) selective A2A receptor agonist regadenoson (other agents will not be discussed here). Whereas in the United States over $80 \%$ of pharmacological stress tests are performed with regadenoson, in part due to its simple protocol with a single injection bolus allowing high-throughput clinical care, ${ }^{4}$ use of other vasodilators is still very common, supported by a large body of evidence demonstrating their efficacy and their lower cost. ${ }^{5,6}$

Mechanistically, dipyridamole inhibits adenosine re-uptake across endothelial and erythrocyte cell membranes, resulting in the increased availability of adenosine at the tissue level, thereby acting as an indirect coronary artery vasodilator. ${ }^{6}$ Dipyridamole has a relatively slow onset of action, with a peak vasodilatory effect within 3 to 7 minutes from beginning of infusion, a tri-exponential elimination half-life of 3 to 12 minutes, 33 to 62 minutes, and 11.6 to 15 hours, ${ }^{5}$ and a hyperemic effect lasting for more than 15 minutes. ${ }^{6}$

Following initial description of intracoronary adenosine mediated vasodilation in humans ${ }^{7}$ and the feasibility of intravenous adenosine infusion to induce coronary hyperemia, ${ }^{8}$ multiple strategies comparing vasodilators have been developed. Since its adoption in clinical practice over 5 decades ago, various dipyridamole protocols have been proposed to induce maximal coronary hyperemia. ${ }^{9-12}$ Compared to adenosine (140 $\mu \mathrm{g} / \mathrm{kg} / \mathrm{min})$, initial work in a small number of patients suggested numerically inferior but statistically insignificant differences in achieved maximal hyperemia using $0.56 \mathrm{mg} / \mathrm{kg}$ dipyridamole infusion over 4 minutes, with 
flow measured by an intracoronary Doppler-flow wire 4 minutes after infusion completion. ${ }^{13}$ Additional observations similarly suggested that a standard dose of dipyridamole $0.56 \mathrm{mg} / \mathrm{kg}$ infused over 4 minutes may result in submaximal coronary vasodilation, ${ }^{14}$ proposing instead a dose of $0.84 \mathrm{mg} / \mathrm{kg} .{ }^{15}$ However, subsequent research demonstrated that a dipyridamole dose of 0.56 $\mathrm{mg} / \mathrm{kg}$ infused over 4 minutes, followed by stress imaging 4 minutes after the end of infusion, gave rise to myocardial flow reserve (MFR) values $(4.0 \pm 1.3)$ comparable to adenosine $(4.3 \pm 1.6)$ using ${ }^{13} \mathrm{~N}$-ammonia PET in normal subjects. ${ }^{16}$ Further, using the same dipyridamole dosage of $0.56 \mathrm{mg} / \mathrm{kg}$ infused over 4 minutes, followed by stress imaging 3 minutes after the end of infusion with ${ }^{15} \mathrm{O}$-labeled water PET, yielded no significant difference compared with adenosine triphosphate (ATP)-induced hyperemia. ${ }^{17}$ In contemporary clinical practice, the most routinely used protocol is dipyridamole $142 \mu \mathrm{g} / \mathrm{kg} / \mathrm{min}$ infusion for 4 minutes (= $0.56 \mathrm{mg} / \mathrm{kg}$ ), followed by PET radiopharmaceutical injection 4 minutes after the completion of dipyridamole infusion. $^{18}$

In the present study, the authors observed no differences between the 2 dipyridamole protocols in stress MBF, MFR, or stress coronary vascular resistance index. Whereas a numerically higher $7.7 \%$ 'suboptimal' rate of maximal hyperemia (defined as MFR $<2$ ) in the 4minute group compared to $3.7 \%$ in the 5-minute group was noted, this was not statistically significant, and may have been at least in part due to differences in disease burden. Indeed, although the authors indicate patients had no apparent obstructive CAD, previous work demonstrated that a CAC score of 0 does not exclude coronary epicardial atherosclerosis, as at least 1 to $2 \%$ and up to 15 to $16 \%$ (depending on the study population) of CAD patients have noncalcified plaques only. ${ }^{19}$ This was likely the case in a segment of the patient population analyzed, given the high prevalence of known cardiovascular risk factors. Further, although the two nonrandomized groups were largely comparable, certain differences in risk-factor profile (BMI and tobacco use) were present.

Whereas American Society of Nuclear Cardiology (ASNC) guidelines recommend injection of the radiopharmaceutical 3 to 5 minutes after completion of dipyridamole infusion to achieve maximal hyperemia, ${ }^{6}$ the authors conducted injections at an earlier 2-minute time-point after completion of dipyridamole infusionboth in the 4-minute and 5-minute infusion protocol. Despite this, the authors emphasize that the stress MBF values obtained were in a range similar to the published literature. ${ }^{18,20}$ Further, as appropriately addressed, in addition to the vasodilatory agent and protocol for induction of maximal hyperemia, the selection of the
PET radiopharmaceutical is also critical. To optimize the absolute MBF assessment by PET, an ideal radiopharmaceutical should exhibit a high first-pass cardiac extraction fraction with the absence of 'roll-off' (plateauing) at high flows, as is observed with ${ }^{82} \mathrm{Rb}$ chloride. ${ }^{21,22}$

Finally, although an ideal study design would have exposed each patient to both dipyridamole dosing protocols, thereby eliminating biases inherent to all retrospective analyses, the present body of work is a welcome addition to our understanding of the physiology of dipyridamole, and supports current clinical practice. This was re-emphasized in the recent joint position paper of the Society of Nuclear Medicine and Molecular Imaging (SNMMI) and ASNC on the clinical quantitation of MBF using PET, with dipyridamole 0.56 $\mathrm{mg} / \mathrm{kg}$ intravenous infusion over 4 minutes with timing interval of radiopharmaceutical injection of 3 to 5 minutes after completion of infusion being the recommended protocol. ${ }^{23,24}$

\section{Disclosure}

None.

\section{References}

1. Harel F, Finnerty V, Authier S, Pelletier-Galarneau M. Comparison of two dipyridamole infusion protocols for myocardial perfusion imaging in subjects with low likelihood of significant obstructive coronary artery disease. J Nucl Cardiol 2018. https://d oi.org/10.1007/s12350-018-01478-x.

2. Joseph J, Velasco A, Hage FG, Reyes E. Guidelines in review: Comparison of ESC and ACC/AHA guidelines for the diagnosis and management of patients with stable coronary artery disease. $\mathrm{J}$ Nucl Cardiol 2018;25:509-15.

3. Gibbons RJ. Comparison of ESC and ACC/AHA guidelines for the diagnosis and management of patients with stable coronary heart disease: Are the differences clinically relevant? An American perspective. J Nucl Cardiol 2018;25:516-20.

4. American Society of Nuclear Cardiology. MedAxiom nuclear survey 2013. J Nucl Cardiol 2014;21(Suppl):5-88.

5. Dilsizian V, Gewirtz H, Paivanas N, Kitsiou AN, Hage FG, Crone NE, Schwartz RG. Serious and potentially life threatening complications of cardiac stress testing: Physiological mechanisms and management strategies. J Nucl Cardiol 2015;22:1198-213.

6. Henzlova MJ, Duvall WL, Einstein AJ, Travin MI, Verberne HJ. ASNC imaging guidelines for SPECT nuclear cardiology procedures: Stress, protocols, and tracers. J Nucl Cardiol 2016;23:60639.

7. Zijlstra F, Juilliere Y, Serruys PW, Roelandt JR. Value and limitations of intracoronary adenosine for the assessment of coronary flow reserve. Catheter Cardiovasc Diagn 1988;15:76-80.

8. Wilson RF, Wyche K, Christensen BV, Zimmer S, Laxson DD. Effects of adenosine on human coronary arterial circulation. Circulation 1990;82:1595-606.

9. Kinsella D, Troup W, Mc GM. Studies with a new coronary vasodilator drug: persantin. Am Heart J 1962;63:146-51. 
10. West JW, Bellet S, Manzoli UC, Mueller OF. Effects of persantin (RA8), a new coronary vasodilator, on coronary blood flow and cardiac dynamics in the dog. Circ Res 1962;10:35-44.

11. Tauchert M. Coronary reserve capacity and maximum oxygen consumption of the human heart. Basic Res Cardiol 1973;68:183223.

12. Gould KL, Westcott RJ, Albro PC, Hamilton GW. Noninvasive assessment of coronary stenoses by myocardial imaging during pharmacologic coronary vasodilatation. 2. Clinical methodology and feasibility. Am J Cardiol 1978;41:279-87.

13. Rossen JD, Quillen JE, Lopez AG, Stenberg RG, Talman CL, Winniford MD. Comparison of coronary vasodilation with intravenous dipyridamole and adenosine. J Am Coll Cardiol 1991;18:485-91.

14. Wilson RF, Laughlin DE, Ackell PH, Chilian WM, Holida MD, Hartley CJ, et al. Transluminal, subselective measurement of coronary artery blood flow velocity and vasodilator reserve in man. Circulation 1985;72:82-92.

15. Rossen JD, Simonetti I, Marcus ML, Winniford MD. Coronary dilation with standard dose dipyridamole and dipyridamole combined with handgrip. Circulation 1989;79:566-72.

16. Chan SY, Brunken RC, Czernin J, Porenta G, Kuhle W, Krivokapich J, et al. Comparison of maximal myocardial blood-flow during adenosine infusion with that of intravenous dipyridamole in normal men. J Am Coll Cardiol 1992;20:979-85.

17. Kubo S, Tadamura E, Toyoda H, Mamede M, Yamamuro M, Magata Y, et al. Effect of caffeine intake on myocardial hyperemic flow induced by adenosine triphosphate and dipyridamole. J Nucl Med 2004;45:730-8.

18. Johnson NP, Gould KL. Regadenoson versus dipyridamole hyperemia for cardiac PET imaging. JACC Cardiovasc imaging 2015;8:438-47.
19. Villines TC, Hulten EA, Shaw LJ, Goyal M, Dunning A, Achenbach S, et al. Prevalence and severity of coronary artery disease and adverse events among symptomatic patients with coronary artery calcification scores of zero undergoing coronary computed tomography angiography. Results from the CONFIRM (Coronary CT angiography evaluation for clinical outcomes an international multicenter) registry. J Am Coll Cardiol 2011;58:2533-40.

20. Goudarzi B, Fukushima K, Bravo P, Merrill J, Bengel FM. Comparison of the myocardial blood flow response to regadenoson and dipyridamole: A quantitative analysis in patients referred for clinical $82 \mathrm{Rb}$ myocardial perfusion PET. Eur J Nucl Med Mol Imaging 2011;38:1908-16.

21. Maddahi J, Packard RRS. Cardiac PET perfusion tracers: Current status and future directions. Semin Nucl Med 2014;44:333-43.

22. Dorbala S, Di Carli MF. Cardiac PET perfusion: Prognosis, risk stratification, and clinical management. Semin Nucl Med 2014;44:344-57.

23. Murthy VL, Bateman TM, Beanlands RS, Berman DS, BorgesNeto $\mathrm{S}$, Chareonthaitawee $\mathrm{P}$, et al. Clinical quantification of myocardial blood flow using PET: Joint position paper of the SNMMI cardiovascular council and the ASNC. J Nucl Cardiol 2018;25:269-97.

24. Murthy VL, Bateman TM, Beanlands RS, Berman DS, BorgesNeto S, Chareonthaitawee P, et al. Clinical quantification of myocardial blood flow using PET: Joint position paper of the SNMMI cardiovascular council and the ASNC. J Nucl Med 2018;59:273-93. 